\title{
The Inability of Primary School to Introduce Children to the Theory of Biological Evolution
}

\author{
Lucia Prinou • Lia Halkia • Constantine Skordoulis
}

Published online: 18 March 2011

(C) Springer Science+Business Media, LLC 2011

\begin{abstract}
A great number of research papers in the English literature of science education present difficulties pupils have in understanding natural selection. Studies show that children have essentialist and teleological intuitive ideas when dealing with organisms and that these biases hinder their ability to understand the theory of evolution by natural selection. Consequently, it is interesting to ascertain if and how the school education offered today deals with the problem, i.e., helps the children confront these biases. To that purpose, this study answered the two following research questions: (a) How is biological evolution presented-from the past to the present day - in the official documentation of primary school education, namely the science curricula and the textbooks of Greece? and (b) what are the conceptions held by Greek primary school teachers of the concepts of evolutionary theory and relevant issues that they have to teach? Our research found that not only are the intuitive ideas not "confronted" but they are also "affirmed" in Greek primary education. This phenomenon, as some other international studies have shown, must not be only a Greek one. A drastic change in the content and structure of primary school curricula and the training of educators is necessary in order to improve and facilitate the teaching of biological evolution.
\end{abstract}

Keywords Primary education - Teachers · Curricula . Textbooks $\cdot$ Natural selection $\cdot$ Adaptation

\footnotetext{
L. Prinou $(\bowtie) \cdot$ L. Halkia $\cdot$ C. Skordoulis

Laboratory of Epistemology and Science Education,

Department of Education,

National and Kapodistrian University of Athens,

Athens, Greece

e-mail: lprinou@primedu.uoa.gr
}

\section{Introduction - Literature Review}

Natural selection proposed by Darwin and Wallace was "a truly revolutionary concept, having never before been suggested by any philosopher" and became the "cornerstone of the modern interpretation of evolution" according to (Mayr 2001, p.115). Despite the fact that natural selection had been conceived as an original idea 100 years previously and had been published in 1859 , it took a very long time before it was adopted by the scientific community. The important obstacles it met with were not only religious beliefs but also secular ones, like essentialist (or typological), teleological beliefs, etc. (Mayr 1991). Natural selection was finally accepted after the 1930s, when the evolutionists realized "that none of the explanations of evolution based on the dominant way of thinking of the period-essentialism-was valid," says (Mayr 2001, p.115). And as he notes further down, "even today many people have difficulty understanding how natural selection works. Yet when population thinking is employed, it would seem simplicity itself" (Mayr 2001, p.115).

A great number of research papers in the English literature of science education confirm Mayr's aforementioned findings, regarding the difficulties in understanding natural selection (for a documented presentation, DemastesSoutherland et al. in Good et al. 1992; and recently, Gregory 2009).

According to various researchers, many pupils have a plethora of misconceptions about evolution, including Lamarckian misconceptions (Enderle et al. 2009; Lucas 1971; Deadman and Kelly 1978; Brumby 1979, 1984; Bishop and Anderson 1985; 1990; Greene 1990; JiménezAleixandre 1992, 1996; Passmore and Stewart 2002). The misconceptions are called "Lamarckian" because "organisms can develop new adaptive characteristics in 
response to environmental demands -which is- a Lamarckian principle" (Samarapungavan \& Wiers 1997, p. 148) ${ }^{1}$.

Related research done in Greece (Prinou et al. 2008) has shown that even though pupils accepted biological evolution, they did not use the concept of natural selection in their explanations, but invoked pre-Darwinian explanations instead, which referred to those described by Mayr (1991; 2001). The pupils - despite the fact that they had been taught the theory of evolution ostensibly in the ninth grade - treated organisms as a unified total of almost identical individuals which acquire new traits in order to deal with the needs of the environment. Following that, organisms inherit the new traits to their offspring.

This goal-directed (teleological ${ }^{2}$ ) reasoning noted in the pupils' explanations regarding the origin of biological adaptations, proves to be the predominant one used by pupils of various ages (Abrams et al. 2001; Southerland et al. 2001) but also by educated adults, well-disposed towards the theory of evolution (Abraham-Silver and Kisiel 2008 from research done in Great Britain, Canada, and Australia; Evans et al. 2010 from research done in the United States). Evans et al. (2010) also found that the individuals taking part in their research (i.e., visitors of a natural history museum), despite accepting evolution, had no understanding of natural selection. More than half of them were described by the researchers as novice naturalistic reasoners because they used more the "goal-directed," "need-based" adaptation as the mechanism of evolutionary change rather than natural selection.

A recent study exploring students' explanations about evolutionary relations depicted in noncladogenic diagrams,

\footnotetext{
${ }^{1}$ In more detail: these conceptions of the pupils are called Lamarckian because "the capacity of organisms to react to special conditions in the environment" (which does not occur directly but by a chain of events/ complex mechanisms which Lamarck describes in his work) was considered by Lamarck as the second cause of evolutionary change, according to Mayr (1982). The first cause for Lamarck was an endowment, which provides for the acquisition of ever greater complexity (perfection). The belief in an inheritance of acquired characters is the "second law" of Lamarck, while his "first law" was the principle of use and disuse. Both were beliefs universally accepted at his time, which Lamarck applied to evolution.

"The crucial difference between Darwin's and Lamarck's mechanism of evolution is that for Lamarck the environment and its changes had priority. They produced needs and activities in the organism which in turn caused adaptational variation. For Darwin random variation was present first, and the ordering activity of the environment ('natural selection') followed afterwards," Mayr (1982, p.354).The term "Lamarckian" ideas should not be considered as derogatory for Lamarck and his work, like the term "Aristotelian ideas" does not denigrate Aristotle and his work. Either way, Lamarck has gained his place in the history of science because his work signals the first impressive appearance of evolutionism (Understanding Evolution 2010)

2 "goal-directed" and "teleological" are synonyms in the Greek language in which "telos" means goal
}

Catley et al. (2010) also found that the students used the teleological (purpose-driven) conception of evolution in which organisms change in order to cope better with a new environment and as a result they turn into a new species.

The finding that conceptual biases which hinder the understanding of natural selection exist since early childhood is a common one (Samarapungavan and Wiers 1997; Kelemen 1999; Bloom and Weisberg 2007; Shtulman and Schulz 2008; Sinatra et al. 2008; Gregory 2009).

In one of their studies about children's ideas on the origin of the species, Samarapungavan and Wiers (1997) found that most children used consistent explanatory frameworks which briefly were: (a) the pure essentialist framework (according to which "species have always existed and are immutable"), (b) the dinosaur essentialist framework (according to which in the beginning the earth was populated by the dinosaur ancestors of modern species which underwent micro-adaptational changes in response to a changing environment), (c) the spontaneous generation framework (according to which species originate through spontaneous generation from plant matter or soil), (d) the creationist framework, and (e) the Lamarckian framework. The common denominator in which all five consistent frameworks differ from New-Darwinian theory, is their neglect of the phenomenon of within species variability. "The five frameworks treat within species variation as uninteresting or trivial phenomenon", Samarapungavan and Wiers (1997, p.168) point out.

Also, according to Sinatra et al. (2008), children have essentialist, teleological, and-very closely relatedintentional biases that make learning about evolution very challenging, because, according to them, evolution does not "work." With reference to Gelman (2003), the writers say that "children's essentialism is the tendency to believe that things belong to categories because they have an underlying nature that we cannot see, but which sorts their basic identity" (Sinatra et al. 2008, p. 190). Also, according to their teleological reasoning and the closely related intentionality constraints, children have the inclination to think that "events are not only purposeful but that may be caused by an intentional agent" (Sinatra et al. 2008, p.191).

Nevertheless, Evans $(2005 ; 2008)$ found that children (about ten years old and from non-fundamentalist religious communities) - particularly children who are exposed to evidence of metamorphosis, adaptive variation within species, or fossils - may be capable of accepting that major evolutionary changes occur in organisms and that a species of animal could have evolved from earlier and very different species of living being. However, they probably have many misconceptions about evolution.

Hatano and Inagaki (1997, p.119-120) reckon that "because naive biology assumes living things, but not non-living things, to be able to adjust to their ecological 
niche or ways of life, children are ready to accept any biological species gradual adaptive changes over generations, and thus to form a version of the Lamarckian idea of evolution." Hatano and Inagaki (1997, p. 120) also note that "as children learn these and other scientific conceptions in school biology, their ways of understanding the biological world may in fact change. In other words not only is school biology learned meaningfully by being assimilated into existing knowledge of naïve biology, but also as claimed by Vygotsky (1978), it reorganizes naïve biology by adding, say, physiological mechanisms and the evolutional perspective, so that the reorganized body of knowledge can effectively be used as the basis for answering a wider variety of biological questions."

As a result, it would be interesting to ascertain if and how school education offered to children today, contributes to the reorganization of their naïve biology; in other words, whether concepts of the theory of evolution are systematically introduced during primary education. To that purpose, we posed the two following research questions.

\section{Research Question 1}

The first research question focuses on the directives given to the teachers by the official state, as stated in the curricula and school textbooks. The question is: How is biological evolution presented - from the past to the present day - in the official documentation of school education, namely the primary science curricula and the textbooks of Greece? Do these primary curricula and textbooks contain evolutionary concepts or prerequisite concepts of the evolutionary theory and, if they do, how are said concepts presented?

\section{Research Question 2}

The second research question focuses on the teachers who, on one hand are the mediators between scientific knowledge and school knowledge and, on the other, are considered reliable and trustworthy individuals by their pupils, who usually greatly influence their views (Bloom and Weisberg 2007).

The questions are: (a) what are the conceptions held by primary school teachers of the concepts of evolutionary theory which they have to teach? (b) How well do they know and understand the theory; what is their opinion of their training in evolutionary theory and of their need to be trained in it?

In this paper, we present and combine two separate studies: one referring to Greek primary school science curricula and textbooks and one referring to Greek primary school teachers. This is done in an effort to achieve a fuller and better understanding of the subject under research. Nota bene, that this is the first time that such a study has been carried out in our country. Previous studies done in Greece were researching the various factors that influence the teaching of the evolutionary theory only in secondary education (Prinou et al. 2008).

\section{Methodology}

Methodology of the Study Used in Curricula and Textbooks

The methodology regarding the first research question was as follows: All relevant scientific curricula and textbooks used in the past and up to the present in primary education in Greece were located and underwent an analysis regarding the evolutional concepts they contained. Every concept relevant to evolution that was found was used in the study. Following that, the way the concepts were presented was evaluated.

We must note that in Greece

1. Primary (synonymous with elementary) education includes grades one to six, including the sixth

2. The same curriculum is followed obligatorily in all primary (elementary) state schools in the country and

3. School textbooks written according to this curriculum are published by a state-owned organization that publishes teaching textbooks exclusively, which are then distributed gratis to pupils. Each pupil uses exclusively one specific textbook which is the sole and indisputable source of learning for the pupils and teaching material for the teachers. There are no school textbooks published by private publishing houses. At the same time, the same state organization publishes the textbooks for the teachers of each grade (teacher's textbook). In the study, all the students' textbooks were analyzed - one for each grade - and so were all the teachers' textbooks - also one for each grade.

Twenty-four textbooks in total, i.e., six textbooks for the pupil and six textbooks for the teacher, which were used during the first time period under study (from the beginning of 1980 to nearly 2000) and another set of six textbooks for the pupil and six for the teacher for the second time period (from 2000 to date). ${ }^{3}$

\footnotetext{
${ }^{3}$ The names of the textbooks - from the beginning of 1980 to nearly 2000 - for grades one to four were We and the World; Study of the Environment and for grades five to six were I Inquire the Natural World. The names of the textbooks - from circa 2000 to date-for grades one to four are Study of the Environment and for grades five and six I Inquire and Discover. They are all published by the Greek state publishing organization of school textbooks
} 
Methodology of the Study Used for the Teachers' Conceptions

The methodology used to answer the second research question was the following: The research instrument used for registering the teachers' conceptions and viewpoints was a questionnaire consisting of open-ended and multiple choice questions. Regarding the selection of issues to be investigated, as well as the choice and combination of questions, reference was made to the relevant literature on evolution education (e.g., Lucas 1971; Brumby 1979, 1984; Bishop and Anderson 1990; Rutledge and Warden 2000) as well as the relevant references of the Greek primary curriculum and textbooks. Before the beginning of the study, the questionnaire underwent investigative pilot testing and was modified as needed until it reached its final form. The teachers were not told at the beginning that the questionnaire concerned the theory of evolution, and the open-ended questions were presented first. The SPSS statistical program and content analysis were used to process the replies.

The research sample comprised 153 primary education teachers from Athens (the capital of Greece) and the provinces of the country. The composition of the sample was the following: some $66.4 \%$ women, $33.6 \%$ men; average age, 37 years; average years of service, 11 years; Average time elapsed since graduation, 16 years; $56.9 \%$ had attended training courses, $41.2 \%$ had not ( $2 \%$ did not reply).

\section{Results}

Evolutionary Concepts in Primary School Curricula and Textbooks

Our research showed that until the beginning of the 1980s, primary education curricula and textbooks with biological subjects were only natural history textbooks. These natural history textbooks contained a systematic examination of the organisms of plants, animals, and humans, together with the display of a characteristic representative of each species. They did not contain any references to concepts pertaining to evolutionary theory.

After 1982, the curricula of the primary school's subjects started to change gradually and new textbooks for subjects also containing concepts from biological sciences were gradually introduced. These curricula and textbooks were kept until the beginning of the 2000s. The results are presented in detail in paragraph $\mathrm{A}$, set out below.

The next change of both curricula and textbooks started gradually after the beginning of the new decade. These are the curricula and textbooks used to date. The results are presented in detail in paragraph $\mathrm{B}$, which follows.
A. From the Beginning of the 1980s until circa 2000

The biological subjects which were taught until the fourth grade included, inter alia, the introduction to the world of plants and animals. In the curricula of these subjects, the meaning of "adaptation" was introduced, together with relevant examples. The instructions of the curricula included the objective that pupils be made to "understand the concept of adaptation" and the "ways" by which plants and animals adapt to the environment, as shown in the relevant excerpts (in italics and quotation marks) from the curricula and the textbooks of both pupils and teachers (Table 1).

In the teacher's fourth grade textbook and, specifically, in the chapter entitled "How plants and animals adapt" it was mentioned that "with regard to the phenomenon of adaptation, more systematic research is attempted with small experimental trials carried out by the children themselves and an introduction to the concept of natural selection. We are not discussing the concept of the evolution of the species."

The lesson began with the tropisms of plants and the reactions of animals to environmental stimuli and went on to examples of "adaptation" like various hereditary features of animals (e.g., the white color of the polar bear, various birds' shape of the beak, migration, etc.). The questions addressed to the pupils focused on the purpose for which each animal has these features. After that, references were made to animals that lived in other geological eras.

The science curricula of the other two grades (fifth and sixth) included short sketchy references to concepts relative to the evolution of the organisms, e.g., fossils, pre-historic animals, etc. The notion that was formulated was that the organisms were transformed, aiming towards perfection. The subject of color adaptation kept coming back (see Table 1).

In addition to that, the analysis of all the curricula and textbooks also showed that the way the organisms are presented has the following characteristics:

Organisms of every species are presented as absolutely identical to their ancestors. They are classified in various categories which seem to consist of identical members, embodied in one representative.

The concept of intra-species variation - the existence of differences between members of a population of a speciesdoes not exist at all, i.e., it is not to be found in any curricula or textbook.

\section{B. From circa 2000 to Present}

Curricula and textbooks for many different grades (second, third, and sixth) include only the subject "Adaptation of plants and animals to their environment," as shown in Table 2 which follows. All the examples used refer to hereditary characteristics, e.g., kind of flowers, leaves, migration, hibernation, etc. 
Table 1 From the beginning of 1980s until c2000

\begin{tabular}{|c|c|}
\hline Gr. & Curricula (objectives-basic content) \\
\hline Second & $\begin{array}{l}\text { Pupils "comprehend the meaning of } \\
\text { adaptation of plants and animals and the } \\
\text { relevant concepts" }\end{array}$ \\
\hline Third & $\begin{array}{l}\text { "How does a plant... or animal adapt to the } \\
\text { environment" }\end{array}$ \\
\hline Fourth & $\begin{array}{l}\text { "Emphasis in the study of the way of their } \\
\text { adaptation to the natural habitat and their } \\
\text { struggle for survival,...in the } \\
\text { comprehension of evolutional changes } \\
\text { due to natural conditions" } \\
\text { "How do animals and plants adapt" }\end{array}$ \\
\hline
\end{tabular}

Teachers' textbooks (instructions to teachers)

\section{Adaptation implied}

Examples "Pupils should ascertain the way by which
animals... adapt to their natural environment..."

"How do animals and plants adapt 1. Pupils should be made to observe characteristic reactions of plants and animals to particular stimuli of the environment and to try to interpret their behavior..."

2."Beginning from the pre-mentioned "characteristic examples-experiments"... the investigation and transfer-application of this cognitive structure is achieved by deduction in examples of adaptation of animals"

"Why, for what reason, for what purpose" does each animal have characteristic organs?"

Examples of color adaptation

3. Reference also to animals that lived many geological eras ago

The Earth source of goods: The first human interventions...

Fifth Heredity: inherited and acquired characteristics

Stratums

Fossils

Geological eras

\section{Sixth Amphibia}

Reptiles
First humans - first tools, etc.

Acquired characteristics are not inherited

Fossils

Geological eras

Paleontological findings - bonds between organisms, example

\section{Archaeopteryx}

Color adaptation

The frog's color adaptation to its environment
Pupils' textbooks

Examples

Examples

"How do plants and animals adapt"

1. Example: "Phototropism: Plants in order to find the light are obliged to climb up. Due to this necessity they grow specific organs"

"Every animal in order to survive reacts to its environment... Thus they manage to comply with the demands of life, i.e., they adapt to their environment"

2. Examples of "adaptation of animals," i.e., body shape, shape of beak, etc.

"The different species... adapt their color to match their surroundings so well in order to go undetected by their enemies"

3. Dinosaurs, mammoths

First humans-creation of tools, etc.

Acquired characteristics are not inherited

Fossils, pre-historic animals, mammoths, geological eras. "The first to appear on earth were the simple organisms and, gradually, the more accomplished ones"

\footnotetext{
"The phenomenon of the frog adapting its color to match the color of its surroundings is called color adaptation."

"Millions of years ago, lived on earth animals with a characteristic shape and size"
}

Table 2 shows that in all grades the verb "adapt" is used in the present tense and active voice. In the teacher's textbook of the first grade, there is a reference to the "evolutionary course of plants," but there are no other relevant explanations. In the teacher's textbook of the sixth grade, the explanation given is that "In order to survive, every animal adapts to its habitat." "The adaptive ability of every animal is the result of the action of natural selection and phenotypically it expresses itself in the color of the animal...in its individual characteristics, as well as in the particular behavior that it develops." Then it is mentioned in examples which are worded as follows: “...Fish and birds of tropical regions have vivid colors, in order to blend in with their environment...Aquatic animals, fish as well as mammals, have a hydrodynamic shape, in order to minimize the friction during their movement in the water."

Other concepts relevant to the evolution of the species are not mentioned in any grade, except for one cursory reference to dinosaurs in the sixth grade.

The analysis of all curricula and textbooks showed also that the way organisms are presented has the following characteristics: 
Table 2 From c2000 to date

\begin{tabular}{|c|c|c|c|}
\hline Gr. & Curricula & Teachers' textbooks & Pupils' textbooks \\
\hline \multirow[t]{3}{*}{ Second } & \multirow[t]{3}{*}{$\begin{array}{l}\text { "Adaptation of the animals to the } \\
\text { environment" }\end{array}$} & $\begin{array}{l}\text { "...A synopsis of the animals' basic needs is } \\
\text { given... and the new concept of adaptation } \\
\text { to the environment is introduced" }\end{array}$ & $\begin{array}{l}\text { "Animals adapt to the environment. } \\
\text { Animals find different ways to adapt to } \\
\text { the environment in order to survive ... } \\
\text { Some birds migrate... etc. But others find } \\
\text { it hard" }\end{array}$ \\
\hline & & \multirow[t]{2}{*}{$\begin{array}{l}\text { "Plants in their evolutionary course } \\
\text { perfected the...mechanisms and the } \\
\text { functions necessary to the production of } \\
\text { their food etc.... as well as their ability to } \\
\text { adapt to their natural environment" }\end{array}$} & $\begin{array}{l}\text { "Nothing is accidental... in plants... Plants } \\
\text { find clever ways to protect themselves, and } \\
\text { to adapt to the environment. The plants use } \\
\text { "clever" ways to feed themselves, to } \\
\text { protect themselves from their enemies... } \\
\text { They adapt, that is, to the environment" }\end{array}$ \\
\hline & & & Examples \\
\hline \multirow[t]{3}{*}{ Third } & \multirow{3}{*}{$\begin{array}{l}\text { The pupils must "comprehend that the } \\
\text { plants form their characteristics } \\
\text { according to the condition of the } \\
\text { environment in which they grow" } \\
\text { And that the animals "adapt to their } \\
\text { habitat in order to survive" }\end{array}$} & \multirow{3}{*}{$\begin{array}{l}\text { Pupils "should ascertain several ways by } \\
\text { which plants adapt to their environment. } \\
\text { Students also discuss the way humans } \\
\text { adapt to the weather..." } \\
\text { "...Highlight the mechanisms by which sea } \\
\text { animals adapt to the (e.g., fish-tail, fins, } \\
\text { body shape" }\end{array}$} & $\begin{array}{l}\text { "When we humans cannot live in a place } \\
\text { we decide to leave. But the plants which } \\
\text { cannot do that, manage by other ways to } \\
\text { adapt to the environment so that they }\end{array}$ \\
\hline & & & $\begin{array}{l}\text { live...How do we humans adapt to the } \\
\text { cold of the winter and the heat of the } \\
\text { summer?...Every animal adapts to the } \\
\text { environment, i.e., has found its own } \\
\text { "solution" in order to live in it. }\end{array}$ \\
\hline & & & $\begin{array}{l}\text { e.g., Fish have long and thin bodies, fins, } \\
\text { and tails, so that they can swim fast in } \\
\text { the water. They all adapt on order to live } \\
\text { in the environment of the water" }\end{array}$ \\
\hline \multirow[t]{3}{*}{ Sixth } & \multirow[t]{2}{*}{$\begin{array}{l}\text { "Characteristics of big mammals, } \\
\text { adaptations to their habitat, herbivores- } \\
\text { carnivores" }\end{array}$} & $\begin{array}{l}\text { "In order to survive, every animal adapts } \\
\text { to its habitat. The adaptive ability of } \\
\text { every animal is the result of the action of } \\
\text { natural selection and phenotypic ally it } \\
\text { expresses itself in the colour of the } \\
\text { animal,...in its individual characteristics, } \\
\text { as well as in the particular behavior that } \\
\text { it develops" }\end{array}$ & $\begin{array}{l}\text { "Adaptation of the animals to the } \\
\text { environment" }\end{array}$ \\
\hline & & $\begin{array}{l}\text { "We introduce the concepts of "adaptation" } \\
\text { and "survival," and we explain them to } \\
\text { the pupils" }\end{array}$ & Examples \\
\hline & Vertebrates & Vertebrates & $\begin{array}{l}\text { "One of the most impressive animals, } \\
\text { which have vanished many centuries } \\
\text { ago, are the dinosaurs" }\end{array}$ \\
\hline
\end{tabular}

Organisms of every species are presented as absolutely identical to their ancestors. They are classified in various categories which seem to consist of identical members, embodied in one representative.

The concept of intra-species variation - the existence of differences between members of a population of a speciesdoes not exist at all, that is, they are not to be found in any curricula or textbooks.

\section{Teachers' Conceptions}

\section{Answers to Open-Ended Questions}

First Open-ended Question: Teachers were given the complete sentence from the teacher's textbook which says that: "Every animal in order to survive adapts to the environment in which it lives... (a fact that) ... is the result of the action of natural selection." They were asked to write how they would answer a hypothetical question asked by one of their pupils which would express the query: "How-in what way-do animals 'adapt'?"

The content analysis of their answers led to the compilation of Table 3 .

As shown in Table 3, only a minor percentage of the teachers $(4.6 \%)$ answered using the scientific explanation, that is, using in some way the concept of natural selection, in their reply. In their majority the teachers answered: 
Table 3 Answers to the first open question

\begin{tabular}{|c|c|c|c|}
\hline 1. & Scientific view & 7 & $4.6 \%$ \\
\hline \multirow[t]{2}{*}{2.} & $\begin{array}{l}\text { a. Answers that invoke examples of animals that "change their characteristics -they have mechanisms } \\
\text { of adaptation... in order to..., so as to..." }\end{array}$ & 70 & $45.8 \%$ \\
\hline & b. Answers using anthropomorphic expressions "The animals are obliged to alter/learn to..." & 37 & $24.2 \%$ \\
\hline 3. & Did not answer & 28 & $18.3 \%$ \\
\hline \multirow[t]{2}{*}{4.} & Other answers & 11 & $7.2 \%$ \\
\hline & TOTAL & 153 & 100.0 \\
\hline
\end{tabular}

1. Invoking examples of animals which change their characteristics - use mechanisms of adaptation.

2. Using anthropomorphic expressions:

Representative examples of answers:

"Animals adapt to their habitat by adopting the color of the flora..." (questionnaire, q, no.143)

"They adapt, e.g. by changing the color of their coat or plumage so as to avoid enemies" (q. no.91)

"Every animal has by nature those mechanisms that allow it to change every time and in every environment, in order to be able to live without any problems"'(q. no.34)

"We give the example of man's ancestor who lived in trees and needed a tail. When man came down from the trees he did not need it anymore, so it atrophied and fell off. The same thing happened to other organs man did not need" (q. no.82)

Second Open-ended Question: Teachers were asked to answer how they would explain to their pupils an item of news referring to the ineffectiveness of insecticides due to the insects' resistance to them.

The content analyses of their answers lead to the compilation of Table 4.

As shown in Table 4, only a minor percentage of the teachers $(4.6 \%)$ use the concept of natural selection in their answers.

The majority explained (detailed in Table 4) that insects

1. “Are able to adapt-to mutate," “...learn how to... manage to adapt to insecticides," and

2. "created antibodies-became immune" etc.
Example: "All species try to adapt to the environment and survive, and therefore develop...mechanisms in order to achieve that. We give various examples from the theory of the evolution of the species, in order to make the phrase more comprehensible" (q. no.31)

Answers to the Multiple-Choice Questions

The teachers' answers to multiple-choice questions are presented in Table 5. As shown in Table 5:

1. The vast majority of teachers appear to accept the evolution of the species and that the theory of evolution also applies to humans.

- The correlation of teachers' answers (a) in that the theory of evolution also applies to humans and (b) teachers' sexes, proved to be statistically significant with $\chi^{2}=11,160$ and $p$ value $=0.004<0.05$ and showed that humankind's evolution is accepted by the majority of the teachers of both sexes.

- The correlation of teachers' answers (a) on that the theory of evolution also applies to humans and (b) the years elapsed since graduation, proved to be statistically significant with $\chi^{2}=20,669$ and $p$ value $=0.002<0.05$ and showed that humankind's evolution is accepted by the majority of teachers who had graduated in different years.

- The correlation of teachers' answers (a) on that the theory of evolution also applies to humans and (b) whether teachers had attended training courses, proved to be statistically significant with $\chi^{2}=6,456$ and $p$ value $=0.040<0.05$ and showed that human-

Table 4 Answers to the second open-ended question

\begin{tabular}{|c|c|c|c|}
\hline 1 . & Scientific view & 7 & $4.6 \%$ \\
\hline 2. & a. Insects "are able to adapt, to mutate..", "they learn to, manage to adapt..." to insecticides & 43 & $28.1 \%$ \\
\hline & b. Insects "got used of insecticides_created antibodies_-became immune," etc. & 49 & $32.0 \%$ \\
\hline 3. & $\begin{array}{l}\text { Tautological answers or answers that attribute the ineffectiveness to "atmospheric change-destruction of the environment", } \\
\text { etc. }\end{array}$ & 30 & $19.6 \%$ \\
\hline 4. & Did not reply & 24 & $15.7 \%$ \\
\hline & TOTAL & 153 & 100.0 \\
\hline
\end{tabular}


Table 5 Teachers' answers to multiple-choice questions

\begin{tabular}{|c|c|c|c|c|c|}
\hline Statements & $\begin{array}{l}\text { Absolutely } \\
\text { disagree } \\
\%\end{array}$ & $\begin{array}{l}\text { Probably } \\
\text { disagree } \\
\%\end{array}$ & $\begin{array}{l}\text { Probably } \\
\text { agree } \\
\%\end{array}$ & $\begin{array}{l}\text { Absolutely } \\
\text { agree } \\
\%\end{array}$ & $\begin{array}{l}\text { Don't know, } \\
\text { no reply } \\
\%\end{array}$ \\
\hline & \multicolumn{5}{|c|}{ Evolution of organisms } \\
\hline All organisms on earth came into existence at the same time & 81 & 11.8 & 3.3 & 2 & 2 \\
\hline $\begin{array}{l}\text { Millions of years ago, there existed exactly the same (species of) } \\
\text { plants and animals as those in existence today }\end{array}$ & 71.9 & 22.2 & 3.9 & 0.7 & 1.3 \\
\hline \multirow[t]{2}{*}{ The theory of evolution refers to all organisms except humans } & 63.4 & 25.5 & 3.9 & 5.2 & 2 \\
\hline & \multicolumn{5}{|c|}{ Common ancestry } \\
\hline \multirow{2}{*}{$\begin{array}{l}\text { All species of organisms are descendants of a common distant } \\
\text { ancestor }\end{array}$} & 16.3 & 23.5 & 32 & 18.3 & 15 \\
\hline & \multicolumn{5}{|c|}{ Humans and dinosaurs - origin of life on earth } \\
\hline At one time, people co-existed with dinosaurs & 31.4 & 22.9 & 21.6 & 11.1 & 13.1 \\
\hline \multirow[t]{2}{*}{ Evolution is a theory that explains how life began on earth } & 13.7 & 19 & 39.2 & 24.8 & 3.3 \\
\hline & \multicolumn{5}{|c|}{ Reasons for the appearance of new features-natural selection } \\
\hline $\begin{array}{l}\text { New features appear in organisms because organisms need them in } \\
\text { order to survive }\end{array}$ & 3.3 & 2 & 39.2 & 53.6 & 2 \\
\hline \multirow{2}{*}{$\begin{array}{l}\text { Natural selection occurs every time organisms try to adapt to the needs } \\
\text { of the environment }\end{array}$} & 2 & 5.2 & 49.7 & 37.3 & 5.9 \\
\hline & \multicolumn{5}{|l|}{ "Theory" } \\
\hline Evolution is called a theory because there is no evidence for it & 9.2 & 26.8 & 44.4 & 5.9 & 13.7 \\
\hline
\end{tabular}

kind's evolution is accepted by the majority of teachers who had (but also had not) attended training courses.

2. Nevertheless, only around $50.3 \%$, of the sample of teachers questioned agree with the theory of common ancestry of all species.

3. The vast majority of teachers of primary education accept "need" as the reason for the appearance of new features in organisms.

It is worth mentioning that this view is expressed by:

- The vast majority of teachers of both sexes (correlation which proved to be statistically significant with $\chi^{2}=8,122$ and $p$ value $=0.017<0.05$ ),

- The vast majority of teachers who had (but also had not) attended training courses (correlation statistically significant with $\chi^{2}=8,115$ and $p$ value $=0.017<0.05$ )

Also, the vast majority of teachers who answered the relevant open-ended question, that organisms "adapt" to the environment, also believe that new features appear in organisms because organisms need them in order to survive (correlation proved to be statistically significant with $\chi^{2}=27,767$ and $p$ value $=$ $0.01<0.05$ ).

4. The teachers are confused about the meaning of the concepts of natural selection and adaptation. For the vast majority of educators, "natural selection happens in organisms which try to adapt to the need of the environment."
It was also indicated that the majority (88.7\%) of those who accept that "new features appear in organisms because organisms need them in order to survive" also accept that "natural selection happens in organisms who try to adapt to the need of the environment" (correlation statistically significant with $\chi^{2}=15,525$ and $p$ value $=0.004<0.05$ ).

5. Also, even though dinosaurs are one of the pupils' favorite subjects, especially in primary school, it was evident that only half the sample's teachers know that those organisms disappeared millions of years before humans evolved.

6. Finally, half the educators share the misconception that "evolution is called a "theory" because there is no evidence for it."

Views about the instruction of teachers regarding evolutionary theory and the necessity of said instruction:

7. The vast majority of the teachers $(90 \%)$ "disagree," $58.9 \%$ "absolutely disagree," and $31.1 \%$ "rather disagree" with the notion that "It is not particularly necessary that primary education be informed about the theory of evolution, in order to be able to perform their duties in Primary School."

8. Also, the vast majority of the teachers $(87.3 \%)$ "disagree" (30.0\% "absolutely disagree" and 57.3\% "rather disagree") with "The instruction of primary education teachers (from their graduate studies or their adult education courses) is adequate in order to enable them to handle references relative to the evolution of organisms, when necessary." 


\section{Comments and Conclusions}

The study has shown that until 2000, both in curricula and textbooks for primary education, references to concepts relevant to the evolution of the species were very limited and fragmented. The sentence in the textbook saying that "organisms that appeared later-among whom is man - are more perfect" was a widespread misconception which "can be traced back to the ancient belief that organisms had an innate capacity for improvement, for steadily becoming more perfect" (Mayr 2001, p.150).

In curricula and textbooks used after 2000 to date, the references to evolution are even fewer.

So, while evolution is virtually nonexistent in both the previous and today's curricula and textbooks (of both teachers and pupils), "adaptation" of plants and animals is mentioned but in a highly problematic way. Despite the fact that one of the aims of the section "adaptation of plants and animals," found in a teacher's textbook of an earlier period, was the "Introduction to the concepts of evolution and natural selection," the meanings of the concepts were confused. The meaning of the word "adaptation" within the framework of evolutionary theory was not given at all.

A similar confusion appears when trying to understand the concept of adaptation in today's curricula and textbooks. "Adaptation" is not explained at all in the teachers' textbooks of the lower grades, probably because the explanation is considered superfluous or self-evident, given that the word is used in everyday language as well, or because the writers think that the meaning of adaptation in evolution is the same as the one used in everyday language, or as the meaning the word has in physiology ${ }^{4}$.

So in the corresponding pupils' textbooks (pupils of the lower grades), the authors, by the use of a multitude of

\footnotetext{
${ }^{4}$ Language is yet another obstacle in this matter. The term "adaptation" has a different meaning when used in everyday language and a completely different one when used within the framework of evolution, a fact that was pointed out years ago in the literature of science education (e.g., Lucas 1971; Bishop and Anderson 1985; 1990). Adaptation is, either way, a very problematic concept not only for school biology but also for evolutional biology. In the theory of evolution, it was originally introduced by Darwin, who borrowed it from the work "Natural Theology", by W.Paley, after he radically changed it. Darwin showed that natural selection is capable of forming adaptations, without the need for recourse to occult explanations as done in the work of Paley (Krimbas 1985). Evolutionists have defined the meanings of adaptation, as an improvement in the average ability of the population's members to survive and reproduce in their environment. The term "adaptation" or adaptive trait is also used for a feature that has evolved as consequence of natural selection (Meagher \& Futuyma 2001; Mayr 2001 and Gregory 2009).

In our opinion, it would not be a problem - in order to dispense with the confusion and the difficulties the use of the word brings, especially in younger children (NAS 1998) - if we were to refer in a periphrastic way to the "features" of the organisms and avoid altogether the use of the word in question
}

simplistic phrasings in their explanations, present "adaptation" as an active process undertaken by the organisms in order to achieve their goal.

In the teachers' textbooks of higher grades, as already shown, there is a mention of the concept of natural selection, without adequate explanations. But in the pupils' textbooks, "adaptation" is equaled to the acquirement of characteristic features by organisms, and it implied that adaptation is a process realized by every animal so that it survives in its habitat.

Given such ideas, it is obvious that the teleological viewpoint is used by the school itself (via the texts in the textbooks), in order to explain the origin of the features in organisms. Organisms (which are presented as identical and as if represented by one characteristic type) do change but by "adapting," that is, by acquiring the desired features in order to survive. The concept of the existence of variation among individuals of the same species (a prerogative for the future understanding of natural selection) is nowhere to be found-in either curricula or textbooks-during the whole six years of primary education. These only appear when pupils are taught "natural selection" (i.e., at the end of the ninth grade in secondary school).

Thus, while the study of "teachers' conceptions" shows that they accept biological evolution and especially that of humankind and that half of them accept the common origins of organisms, a much smaller percentage knows how to use natural selection.

The acceptance of a "common origin" by the educators does not mean that they also understand the Darwinian mechanism, as ascertained by the study of Evans et al. (2010) also. The mere mention of natural selection in the teachers' textbooks for higher grades is not enough to equip them with a clear understanding of natural selection.

Indeed, it was evident that a minor percentage of teachers actually interprets the origin of adaptations in a scientific way. The ways by which the majority of the teachers replied (to questions for which they had to use natural selection without its being suggested), refer us back to the aforementioned ambiguous, vague, and unclear explanations mixed with teleological connotations in the textbooks, which, notably, are the only ones published and made available to teachers.

If the curricula and the textbooks had different content, the views of the educators and consequently those of their pupils would be different as well.

For the time being, the teachers "trapped," as they are, in these textbooks, have formed a "novice naturalistic" reasoning (as characterized by Evans et al. 2010) which is similar to the intuitive, goal-directed explanations the pupils offer too. It is obvious that, under these circumstances, no effort is made to question or destabilize the intuitive teleological reasoning of the pupils, and thus the same is carried intact to 
the next levels of education. Naturally, it also influences the teaching of biological subjects in superior grades.

Finally, from all the aforementioned findings, it is evident that primary education in our country is inadequate to introduce the theory of evolution of organisms to children.

But is the inadequacy of teaching the concepts of evolution in primary education just a "Greek" phenomenon or is it seen in other countries as well? Judging by the following international publications on the subject, it is somehow found in other countries too.

According to a joint letter of the British Humanist Association (supported by many great scientific personalities of Britain) about the teaching of evolution in primary education in Great Britain (June 2010), evolution "is a key concept that children should be introduced at an early stage." Nevertheless, "there is no requirement for primary schools to teach evolution and natural selection at all, since this was dropped from legislation in the final days of the last parliament, and the new government has signaled its intention not to proceed with it. This means that children may first encounter the theory of evolution only when they are teenagers, when it is included mandatorily and for the first time in the secondary science curriculum." And according to J. Williams - a specialist in science education who signed the letter, - "misconceptions set in primary will be very difficult, if not impossible, to correct 10 years later" (published in The TES on 3 July, 2009).

Publications that appeared in the 1980s and 1990s (e.g., Keown 1988, Fisher in Good et al. 1992) called attention to the necessity for the construction of a notional understructure for evolution in the curricula and textbooks of primary education in the United States. When Jeffery and Roach (1994) reviewed American textbooks for primary education, they ascertained that the useful understructures of evolution "are not developed throughout the elementary years and thus do not provide the strong framework necessary for students to construct a scientific understanding of evolution" (p. 515). Also, in a recent publication, Wagler (2010) notes the absence of biological evolution from the national standards of the United States for grades K-4 and considers this to affect the students' "educational success when they are introduced to the complex interactions of organisms and environments" and their "overall long-term biological development, i.e., knowledge and application of that knowledge."

Simultaneously, a series of publications (e.g., Asghar et al. 2007 in Canada, Nadelson \& Nadelson 2009 in the United States) shows various difficulties that primary education teachers have teaching evolution.

It is possible that the aforementioned "voids" in primary education, either on the level of curricula and textbooks or of the educators themselves, affect the difficulties that exist in the learning of evolution in older ages as well. For example, it appears that the teaching of evolution only in secondary education is not enough to make pupils adopt anti-intuitive reasoning and avoid any reference to "need" in their evolutionary explanations. But that remains to be seen by applying in practice a long-term program which will train the pupils from a young age to hold an evolutionary attitude towards organisms. And only then shall we be able to ascertain whether we'll encounter the same difficulties we have described in learning about evolution by natural selection (see Review of the Literature).

International literature is full of fruitful proposals which, if carried out, may correct the "errors" and fill the "voids" that exist in curricula and textbooks relative to teaching the concepts of evolution in primary education and at the same time, help the educators complete their education. Such proposals are found in, for instance, the publications of Fail 2008; Nadelson et al. 2009; Chanet and Lusignan 2009, Eldredge \& Eldredge 2009, Wagler 2010, as well as in the tool Benchmarks for Science Literacy (2008) and the Website Understanding Evolution, 2010.

It is known that, in various countries, the teaching of evolution in secondary education meets with difficulties (Kim \& Nehm 2010) evidently affecting its introduction to primary education. But in Greece in particular, we cannot say that there are today "widely publicized anti-evolution movements whose persistent efforts have resulted in state standards that de-emphasize the role in evolution" as there are in the United States (Evans et al. 2010, p.327). It is true that fanatic religious circles, mainly in the past, did openly or covertly react against the teaching of evolution and mainly the origin of humankind (Krimbas 2009). But at least today, this subject does not touch the majority of the rest of the citizens and the educators in particular, who, within the framework of science classes, are the only ones qualified to introduce scientific theories in general and the theory of evolution in particular. What needs to be dealt with is the ignorance of the matter. Given appropriate changes in the structure and content of curricula and textbooks, and appropriate programs for the education and training of teachers, etc., we could introduce the subject of evolution in primary education, a fact that would probably result in the timely and systematic handling the aforementioned anti-intuitive notions of pupils.

\section{References}

Abraham-Silver L, Kisiel J. Comparing visitors' conceptions of evolution: examining understanding outside the United States. Visit Stud. 2008;11:141-54.

Abrams E, Southerland S, Cummins C. The how's and why's of biological change: how learners neglect physical mechanisms in their search for meaning. Int J Sci Educ. 2001;12:1271-81. 
Asghar A, Wiles JR, Alters B. Canadian pre-service elementary teachers' conceptions of biological evolution and evolution education. McGill J Educ. 2007;42:189-209.

Benchmarks for Science Literacy. http://www.project2061.org/publi cations. 2008.

Bishop B, Anderson C. Student conceptions of natural selection and its role in evolution. J Res Sci Teach. 1990;27:415-27.

Bishop B, Anderson CW. Evolution by natural selection: a teaching module. (Occasional Paper No. 91). East Lansing, MI: Institute for Research on Teaching Michigan State University; 1985.

Bloom P, Weisberg DS. Childhood origins of adult resistance to science. Science. 2007;316:996-7.

Brumby MN. Problems in learning the concept of natural selection. J Biol Educ. 1979;13:119-22.

Brumby MN. Misconceptions about the concept of natural selection by medical biology students. Sci Educ. 1984;68:493-503.

Catley KM, Novick LR, Shade CK. Interpreting evolutionary diagrams: when topology and process conflict. J Res Sci Teach. 2010;47(7):861-82.

Chanet B, Lusignan F. Teaching evolution in primary schools: an example in French classrooms. Evo Edu Outreach. 2009;2:136-40.

Deadman JA, Kelly PJ. What do secondary school boys understand about evolution and heredity before they are taught the topics. J Biol Educ. 1978;12(1):7-15.

Eldredge N, Eldredge G. Lessons from EEO: Toward a universal evolutionary curriculum. Evo Edu Outreach. 2009;2:643-54.

Enderle PJ, Smith MU, Southerland S. Does prior knowledge matter? Do Lamarckian misconceptions exist? A critique of Geraedts and Boersma (2006). Int J Sci Educ. 2009;31(18):2527-32.

Evans EM. Teaching and learning about evolution. In: Diamond J, editor. The virus and the whale: explore evolution in creatures small and large. Arlington: NSTA Press; 2005.

Evans EM. Conceptual change and evolutionary biology: a developmental analysis. In: Vosniadou S, editor. International handbook of research on conceptual change. New York: Routledge; 2008. p. 263-94.

Evans EM, Spiegel AN, Gram W, Frazier BN, Tare M, Thompson S, et al. A conceptual guide to natural history museum visitors understanding of evolution. J Res Sci Teach. 2010;47(3):326-53.

Fail Jr J. A no-holds-barred evolution curriculum for elementary and junior high school students. Evo Edu Outreach. 2008; 1:56-64.

Gelman SA. The essential child: origin of essentialism in everyday thought. Oxford: Oxford University Press; 2003.

Good RG, Trowbridge JE, Demastes SS, Wandersee JH, Hafner MS, Cummins CL. Proceedings of the 1992 Evolution Educational Research Conference Baton-Rouge; 1992.

Greene ED. The logic of university students' misunderstanding of natural selection. J Res Sci Teach. 1990;27(9):875-85.

Gregory TR. Understanding natural selection: essential concepts and common misconceptions. Evo Edu Outreach. 2009; 2156-175.

Hatano G, Inagaki K. Qualitative changes in intuitive biology. Eur J Psychol Educ. 1997;12(2):111-30.

Jeffery KR, Roach LE. A study of the presence of evolutionary protoconcepts in pre-high school textbooks. J Res Sci Teach. 1994;31(5):507-18.

Jiménez-Aleixandre MP. Thinking about theories or thinking with theories: a classroom study with natural selection. Int J Sci Educ. 1992;14(1):51-61.
Jiménez-Aleixandre MP. Darwinian and Lamarckian models used by students and their representations. In: Fisher KM, Kibby M, editors. Knowledge acquisition, organization and use in biology. New York: Springer; 1996. p. 65-77.

Kelemen D. Functions, goals and intentions: children's teleological reasoning about objects. Trends Cogn Sci. 1999;12:461-8.

Keown D. Teaching evolution. Improved approaches for unprepared students. Am Biol Teach. 1988;50(7):407-10.

Kim SY, Nehm RH. A cross-cultural comparison of Korean and American science teachers' views of evolution and the nature of science. International Journal of Science Education, iFirst Article. $2010 ; 1-31$.

Krimbas CB. On adaptation, neodarwinian tautology, and population fitness. Evolutionary biology 17: 1-57. New York and London: Plenum; 1985.

Krimbas C. Writing for evolution in textbooks. In: V Zogza et al. (eds.) Teaching the theory of evolution: theoretical and pedagogical issues Athens Geitonas School. 2009; 412-420 (in Greek).

Lucas A. The teaching of adaptation. J Biol Educ. 1971;5:86-90.

Mayr E. One long argument: Charles Darwin and the genesis of modern thought. Harvard University Press; 1991.

Mayr E. The growth of biological thought. Belknap Harvard; 1982.

Mayr E. What Evolution is. Basic Books; 2001.

Meagher TR, Futuyma DJ. The American Naturalist 158 Supplement October 2001; 2001.

Nadelson LS, Nadelson S. K-8 educators perceptions and preparedness for teaching evolution topics. Evo Edu Outreach. 2009;2:156-75.

Nadelson L, Culp R, Bunn S, Burkhart R, Shetlar R, Nixon K, et al. Teaching evolution concepts to early elementary school students. Evo Edu Outreach. 2009;2:458-73.

National Academy of Sciences. Teaching about Evolution and the Nature of Science, National Academy Press; 1998.

Passmore C, Stewart J. A modelling approach to Teaching Evolutionary Biology in High Schools. J Res Sci Teach. 2002;39:(3)185204.

Prinou L, Halkia L, Skordoulis C. What conceptions do Greek school students form about biological evolution? Evo Edu Outreach. 2008; $1: 312-7$.

Rutledge ML, Warden AM. Evolutionary theory, the nature of science \& high school biology teachers: critical relationships. Am Biol Teach. 2000;62(1):23-31.

Samarapungavan A, Wiers RW. Children's thoughts on the origin of species: a study of explanatory science. Cogn Sci. 1997;21(2):14777.

Shtulman A, Schulz L. The relation between essentialist beliefs and evolutionary reasoning. Cogn Sci. 2008;32:1049-62.

Sinatra GM, Brem SK, Evans EM. Changing Minds? Implications of conceptual change for teaching and learning about biological evolution. Evo Edu Outreach. 2008;1:189-95.

Southerland SA, Abrams E, Cummins C, Anzelmo J. Understanding students' explanations of biological phenomena: conceptual frameworks or P-prims? Sci Educ. 2001;85:328-48.

Understanding Evolution. University of California Museum of Palaeontology. 22 February 2010 http://evolution.berkeley.edu/evosite/ Lessons/IIConcepts.php and http://evolution.berkeley.edu/evolibrary/ article/history_09; 2010.

Wagler R. A missing link: K-4 biological evolution content standards. Evo Edu Outreach. 2010. doi:10.1007/s12052-010-0240-2. 